\title{
On Risk Comprehensive Evaluation of Carbon Finance in Commercial Banks under Low-Carbon Economy in China
}

\author{
Wenjuan $\operatorname{Pan}^{1}$ \\ ${ }^{1}$ School of Economics, Northwest University for Nationalities, Lanzhou, China \\ Correspondence: Wenjuan Pan, School of Economics, Northwest University for Nationalities, Lanzhou 730124, \\ China. E-mail: wjpcn@126.com
}

Received: June 17, 2014

Accepted: July 1, 2014

Online Published: September 30, 2014

doi:10.5430/ijfr.v5n4p139

URL: http://dx.doi.org/10.5430/ijfr.v5n4p139

This work was supported by the Fundamental Research Funds for the Central Universities of Northwest University for Nationalities (Grant No.31920140026).

\begin{abstract}
In this paper, the author analyzed four dimensional evaluation index systems for comprehensive evaluation of risk of carbon finance Business under the low-carbon economy in China. The analysis was conducted by means of an AHP-based Approach which builds a system analysis technique for multiple criteria decision making as well as the weighted LEC method and by market risk, credit risk, operational risk and project risk. The result show that evaluation index system based on AHP Algorithm for comprehensive evaluation of risk of carbon finance Business in China has good reliability.
\end{abstract}

Keywords: carbon finance, commercial banks, risks, low-carbon economy, AHP

\section{Introduction}

With the arrival of the era of low-carbon, carbon finance has become an important trend in the global financial industry, and boosts the traditional economic updating and transformation. Carbon finance is a new financial activities that derived from the investment and financing activities of the low-carbon, which services to some technical that limit greenhouse gas emissions and Project financing, carbon trading, bank loans and other financial activities. China's carbon emission trading market is a huge space of the world's financial markets. With the foreign investment banks with sensitive of smell and venture capital funds in the carbon trading quietly enter China, our government has made it clear to the thousand Yuan GDP energy consumption targets must be reduced to 2.1 tons in 2012. China's commercial banks should seize the opportunity and face the challenges, When practice the bank's social responsibility should to actively Participate in carbon finance business. In China, the bank's credit takes financial support to $90 \%$ of production and project development, construction of new Projects. The bank's tendency directly affects the industrial development, and ultimately affects the economic development Patten. Strengthening the commercial banking business of carbon finance and risk research has a very important practical significance.

It is always a focus point on the relationship between financial development and economic growth in theory Beneivenga et al (1991), King et al (1993), Krugman (1995). However, some scholars have carried out the risks research on carbon financial business. Miao XiaoYu (2010) argued that the commercial Banks mainly face the following six kinds of risk in carrying out the carbon finance business: market risk, credit risk, policy risk, legal risk, huge opportunity cost risk, loss of control of carbon currency risk. Qin Xueping (2010) argued that compared with the general investment projects, the examination and approval program development process and the carbon credit approval of CDM project is more complex, the CDM project is developed a long-term process with additional transaction costs. In addition, the development of CDM projects involved in policy risk, project risk, cycle and CDM specific risks and other risk. The general idea of this paper is that on the basis of commercial bank's carbon financial business lines and risk, to evaluate all risks which China's commercial banks to develop carbon finance business by the methods of AHP-based Approach which builds a system analysis technique for multiple criteria decision making as well as the weighted LEC method and by market risk, credit risk, operational risk and project risk. 


\section{The Framework of the Indicators of Risk Screening}

Carbon financial risk in the commercial banks refers mostly risks associated with their own business when commercial banks operate the carbon finance business, mainly including market risk, credit risk, operational risk, project risk.

\subsection{Definition of Indicators}

Market risk refers to the risk of assets loss in commercial bank influenced by market factors of carbon finance, mainly including interest rate risk, exchange rate risk, CERs delivered price risk; Credit risk refers to the risks resulted from failure to fulfilling obligations or change of credit quality of counterparty in the process of investments on CDM projects in which the commercial banks engaged the carbon finance activities, including the risk of non-performing loans ratio of CDM project, contractual capacity on buyer, (real purchases of CERs/committed purchases of CERs), the risk of whether CDM projects put into operation on schedule and whether CDM projects generates the CERs risk under the contract; Operational risk: risk of personnel quality, internal process risk, system defects risk, technology risk, external factor influence risk; Project risk refers to the risks despite the credit risk when the commercial banks invests in CDM projects, including cyclical risk of CDM project development, risk domestic of examination and approval of CDM project, methodology risk for examination and approval of CDM project, verification risks, registration risks, risks of international climate negotiations and force majeure risks, etc.

\subsection{Establishment of Risk Index System}

The principal forms of carbon financial activities in China is given priority to Clear Development Mechanism of CDM projects, and also involving in investment as well as other projects related to energy saving and emission reduction. According to the China banking environment record 2010 (NGO) as well as The Annual CSR reports of various bank in 2009 and 2010 and other documents, proceeding from conveniences and research comprehensiveness of data collection, we preliminary present the above nineteen indicators of risk assessment index system.

\subsection{The Index System Analysis-The Weighted LEC Method}

The formula of the LEC weighted analysis: $\mathrm{D}=\mathrm{L} * \mathrm{E}^{*} \mathrm{C}$, where $\mathrm{D}$ is risk value, $\mathrm{L}$ refers of possibility occurrence to the risk. Due to impossibility of avoiding risks or risks nonoccurrence of carbon finance business in commercial banks, this paper sets the minimum probability of risk as 0.1 , the maximum probability of risk occurrence as 1 , and from $0.1-1$ in between. E stands for risk frequency, generally speaking, the higher the frequency, the greater the risk. we set value 10 for persistent risk and 0.5 of frequency for almost zero risk, and from $0.5-10$ in between. $\mathrm{C}$ is the result of risk occurrence. We use lose to express the results from risk, and set 100 for maximum value and 1 for minimums and 1-100 in between. We use interviews and expert scoring method, by group working discussion, each expert shows their opinions according to the understanding of risk to determine risk index, and then determine the evaluation index. We define comprehensive evaluation of risk of carbon finance business in commercial bank in China as the final objective, directive criteria and the decisive indexes. The hierarchy of decisive indexes is a family of thirteen sustainability indicators. Three indexes are closely interconnected with the Market risk B1 and listed as interest rate risk $\mathrm{C} 1$, exchange rate riskC2, CERs delivered price riskC3; Credit risk B2contains two indicators listed as contractual capacity on buyer $\mathrm{C} 4$, whether CDM projects generates the CERs risk under the contract C5; Operational risk $\mathrm{B} 3$ relates to risk of personnel quality $\mathrm{C} 6$, technology risk $\mathrm{C} 7$, system defects risk $\mathrm{C} 8$; Project risk covers cyclical risk of CDM project development $\mathrm{C} 9$, domestic risk of examination and approval of CDM project $\mathrm{C} 10$, methodology risk for examination and approval of CDM project $\mathrm{C} 11$, verification risks $\mathrm{C} 12$, registration risks C13.

\section{Comprehensive Evaluation of Risk of Carbon Finance Business}

\subsection{Theoretical Methods}

This article sides solidly with $\mathrm{T} \cdot \mathrm{L} \cdot \mathrm{Saaty}$, who is a famous American professor in 1970s advocating analytical hierarchy process as abbreviated by many scholars as AHP. The core philosophy of AHP consists of three stages. Firstly, define clearly the final objective of the research issue, then regroup the concerned sub-issues, form differentiated hierarchy clusters according to the correlations of the chosen sub-standards and set up a hierarchy model to portray the complexity of the involving determinants in a highly-ordered, open structure. Secondly, make a general assessment to the importance of different hierarchy clusters subject to the appraisals from the research scholars, thus conclude the weight value for respective hierarchy clusters. Last, recognize the perceptual analysis and make necessary adjustments to internalize the data, thus while, deduce the ultimate weight value which can clearly indicate how the different hierarchy clusters contribute to the overall resultant objective. 


\subsection{The Construction of the Judgment Matrix Analysis}

\subsubsection{Constructing the Judgment Matrix}

The indexes of the same level are compared one by one to create judgment matrix. For example, if the elements of layer $A$ have relation to the elements of lower layers $B_{1}, B_{2}, \cdots, B_{n}$, the judgment matrix is shown in Table 1 .

Table 1. Judgment matrix of the significant extent of the indexes in layer $B$

\begin{tabular}{cccccc}
\hline$A$ & $B_{1}$ & $B_{2}$ & $\ldots$ & $B_{n}$ & $W_{i}$ \\
\hline$B_{1}$ & $B_{11}$ & $B_{12}$ & $\ldots$ & $B_{1 n}$ & $W_{1}$ \\
$B_{2}$ & $B_{21}$ & $B_{22}$ & $\ldots$ & $B_{2 n}$ & $W_{2}$ \\
$\vdots$ & $\vdots$ & $\vdots$ & $\vdots$ & $\vdots$ & $\vdots$ \\
$B_{n}$ & $B_{n 1}$ & $B_{n 2}$ & $\ldots$ & $B_{n n}$ & $W_{n}$ \\
\hline
\end{tabular}

In the above matrix, $b_{i j}$ shows the significance extent of corresponding $B_{i}$ and $B_{j}$, which takes $1,2,3 \ldots, 9$ and

their reciprocals as its value. When $b_{i j}$ equals to 1 , it shows that $B_{i}$ and $B_{j}$ are same significance; when $b_{i j}$

equals to 3 , it shows that $B_{i}$ is a little more significant than $B_{j}$; when $b_{i j}$ equals to 5 , it shows that $B_{i}$ is more significant than $B_{j}$; when $b_{i j}$ equals to 7 , it shows that $B_{i}$ is much more significant than $B_{j}$; when $b_{i j}$ equals to 9 ,

it shows that $B_{i}$ is extremely more significant than $B_{j}$; when $b_{i j}$ is $2,4,6$ or 8 , it shows that the significance is between above adjacent values; and the corresponding reciprocal show the insignificance extent.

\subsubsection{Construction of the Judgment Matrix}

Through expert ratings of 13 indexes, judgement matrix from B1to B4 as well as A are as follows

$$
B_{1}=\left[\begin{array}{ccc}
1 & 1 / 3 & 1 / 6 \\
3 & 1 & 1 / 5 \\
6 & 5 & 1
\end{array}\right] B_{2}=\left[\begin{array}{cc}
1 & 6 \\
1 / 6 & 1
\end{array}\right] B_{3}=\left[\begin{array}{ccc}
1 & 7 & 6 \\
1 / 7 & 1 & 1 / 2 \\
1 / 6 & 2 & 1
\end{array}\right] \quad B_{4}=\left[\begin{array}{ccccc}
1 & 1 / 3 & 1 / 6 & 1 / 8 & 1 / 7 \\
3 & 1 & 1 / 4 & 1 / 7 & 1 / 6 \\
6 & 4 & 1 & 1 / 6 & 1 / 5 \\
8 & 7 & 6 & 1 & 2 \\
7 & 6 & 5 & 1 / 2 & 1
\end{array}\right] A=\left[\begin{array}{cccc}
1 & 5 & 6 & 1 / 4 \\
1 / 5 & 1 & 3 & 1 / 7 \\
1 / 6 & 1 / 3 & 1 & 1 / 8 \\
4 & 7 & 8 & 1
\end{array}\right]
$$

We adopt consistency adjustment in the AHP model to avoid inconsistency of the judgment matrix $\mathrm{H}$, therefore the concept of consistency index is put into use.

$$
C I=\frac{\lambda_{\max }-n}{n-1}
$$

While $\lambda_{\max }=n, \mathrm{CI}=0$, this implies the judgment matrix is perfectly consistent. The larger the figures of CI result, the lower consistency of the judgment matrix.

Besides the possibly subjective assessments of the participants, the proportion scaling of the pair comparison may affect the consistency of the judgment matrix. The varied acceptable values of CI for differentiated-order matrix demand the RI methodology in our research. That is, we apply the average random consistency index to make the consistency indexes revised so as to avoid the results deviating from the fact. The revised result CR should be

$$
C R=\frac{C I}{R I} \times 100 \%
$$

Generally, for judgment matrix of $n \geq 3$ order, it owes highly acceptable consistency in the case $C R \leq 0.1$. Whist $C R>0.1$ alleges the clear deviation from the harmonious consistency and further indicators amendment is thus indispensable for the satisfactory research results. 


\subsubsection{Resultant Calculation of Indicators}

The concerned data from the assessments of the participant scholars and the answers of the questionnaires serve to illustrate application of the AHP concept. The pair-comparison judgment matrixes of the directive criteria in the AHP model are as follows.

Table 2. B1 Judgment matrix

\begin{tabular}{ccccc}
\hline B1 & C1 & C2 & C3 & Wi \\
\hline C1 & 1 & $1 / 3$ & $1 / 6$ & 0.0881 \\
C2 & 3 & 1 & $1 / 5$ & 0.1947 \\
C3 & 6 & 5 & 1 & 0.7172 \\
\hline
\end{tabular}

The results of Table 2 are $\lambda \max =3.0940, \mathrm{CI}=0.047, \mathrm{RI}=0.052$, and the relevant $\mathrm{CR}=0.0904<0.1$, thus highly acceptable consistency of the judgment matrix.

Table 3. B2 Judgment matrix

\begin{tabular}{cccc}
\hline B2 & C4 & C5 & Wi \\
\hline C4 5 & 1 & 6 & 0.8571 \\
C5 & $1 / 6$ & 1 & 0.1249 \\
\hline
\end{tabular}

The results of Table 3 are $\lambda \max =2.0000, \mathrm{CI}=0, \mathrm{RI}=0$, and the relevant $\mathrm{CR}=0<0.1$, thus highly acceptable consistency of the judgment matrix.

Table 4. B3 Judgment matrix

\begin{tabular}{ccccc}
\hline B3 & C6 & C7 & C8 & Wi \\
\hline C6 & 1 & 7 & 6 & 0.7582 \\
C7 & $1 / 7$ & 1 & $1 / 2$ & 0.0905 \\
C8 & $1 / 6$ & 2 & 1 & 0.1512 \\
\hline
\end{tabular}

The results of Table 4 are $\lambda \max =3.0324, \mathrm{CI}=0.0162, \mathrm{RI}=0.52$, and the relevant $\mathrm{CR}=0.0311<0.1$, thus highly acceptable consistency of the judgment matrix.

Table 5. B4 Judgment matrix

\begin{tabular}{ccccccc}
\hline B4 & C9 & C10 & C11 & C12 & C13 & Wi \\
\hline C9 & 1 & $1 / 3$ & $1 / 6$ & $1 / 8$ & $1 / 7$ & 0.0319 \\
\hline $\mathrm{C} 10$ & 3 & 1 & $1 / 4$ & $1 / 7$ & $1 / 6$ & 0.0568 \\
\hline $\mathrm{C} 11$ & 6 & 4 & 1 & $1 / 6$ & $1 / 5$ & 0.1216 \\
\hline $\mathrm{C} 12$ & 8 & 7 & 6 & 1 & 2 & 0.4637 \\
\hline $\mathrm{C} 13$ & 7 & 6 & 5 & $1 / 2$ & 1 & 0.3224 \\
\hline
\end{tabular}

The results of Table 5 are $\lambda \max =5.4313, \mathrm{CI}=0.0108, \mathrm{RI}=1.12$, and the relevant $\mathrm{CR}=0.0963<0.1$, thus highly acceptable consistency of the judgment matrix.

Table 6. A Judgment matrix

\begin{tabular}{cccccc}
\hline A & B1 & B2 & B3 & B4 & Wi \\
\hline B1 & 1 & 5 & 6 & $1 / 4$ & 0.2605 \\
\hline B2 & $1 / 5$ & 1 & 3 & $1 / 7$ & 0.0852 \\
\hline B3 & $1 / 6$ & $1 / 3$ & 1 & $1 / 8$ & 0.0454 \\
\hline B4 & 4 & 7 & 8 & 1 & 0.6089 \\
\hline
\end{tabular}

The results of Table 6 are $\lambda \max =4.2605, \mathrm{CI}=0.087, \mathrm{RI}=0.89$, and the relevant $\mathrm{CR}=0.0976<0.1$, thus highly acceptable consistency of the judgment matrix.

As indicated in the results of Tables 2 to 6 , all of the single values of CR are below 0.1 , therefore the weight distribution in the judgment matrixes has the best consistency. We seek for further test of the consistency indices for the levels of total order based on the following equation.

$$
C R_{\text {sum }}=\frac{\sum_{j=1}^{n} a_{j} C I_{j}}{\sum_{j=1}^{n} a_{j} R I_{j}}
$$


Table 7. Weight distribution of index Layer $\mathrm{C}$ to target Layer A and ranking

\begin{tabular}{ccccccc}
\hline & B1 & B2 & B3 & B4 & Wi & ranking \\
\cline { 2 - 6 } C & 0.2605 & 0.0852 & 0.0454 & 0.6089 & & \\
C1 & 0.0881 & & & & 0.0229 & 9 \\
C2 & 0.1947 & & & & 0.0507 & 6 \\
C3 & 0.7172 & & & 0.1868 & 3 \\
C4 & & 0.8571 & & & 0.073 & 5 \\
C5 & & 0.1429 & & & 0.0122 & 11 \\
C6 & & & 0.7582 & & 0.0345 & 8 \\
C7 & & & 0.0905 & & 0.0041 & 13 \\
C8 & & 0.1512 & & 0.0069 & 12 \\
C9 & & & 0.0319 & 0.0194 & 10 \\
C10 & & & & 0.0568 & 0.0346 & 7 \\
C11 & & & & 0.1216 & 0.074 & 4 \\
C12 & & & & 0.4637 & 0.2846 & 1 \\
C13 & & & & 0.3224 & 0.1963 & 2 \\
\hline
\end{tabular}

On conditions that $\mathrm{CI}=0.112, \mathrm{RI}=1.216, \mathrm{CR}=0.02325<0.1$, the Table 7 has acquired satisfactory feasibility and validity.

\subsubsection{Analyses Reflections}

By above calculations and analysis we obtain the ranking of various risk of carbon finance in the commercial banks. Analysis confirms that verification risks and registration risks on CDM projects are the major risk; CERs delivered price risk also impacts greatly on the risk of carbon finance in the commercial banks. It is clear to state that project risk is the main source of carbon financial risk in commercial bank and generating significant impact on the carbon finance activities; Market risk is the second largest risk, through changes of the CERs delivered price risk, exchange rate risk affecting benefit from carbon financial activities; contractual capacity on buyer of the credit risk also considerably influence the expected revenues of carbon finance activities; Compared with other risk, operational risk shows less effect on the carbon finance activities in commercial bank.

\section{Conclusions}

An index evaluation system for comprehensive evaluation of risk of carbon finance Business in China is constructed by AHP Algorithm. The ideas in this paper are unique and different from those in the literature. Although it should be noted that the evaluation model is mainly based on experts' numerical scoring through a series of mathematical methods with limited accuracy, the results are still helpful in constituting reasonable policy in the process of evaluation of risk of carbon finance Business in China.

\section{References}

Bencivenga, V., \& Smith, B. (1991). Financial Intermediation and Endogenous Growth. Journal of Review of Economics Studies, 58(2), 195-209.

King, R. G., \& Levine, R. (1993). Finance and Growth: Schumpeter Might Be Right. The Quarterly Journal of Economics, 108(3), 717-737.

Krugman, P., \& Venables, J. A. (1995). Globalization and the Inequality of Nations. The Quarterly Journal of Economics, 110(4), 857-880.

Miao, Xiaoyu. (2010). Carbon finance risk nalysis and the response of Chinese commercial Banks. Journal of rural financial research, (9), 12-16

Qin, Xueping. (2010). The Development of China's Carbon Finance and Carbon Finance Mechanism Innovation Strategy. Shanghai Finance, (10), 23-29.

Ren, W. F. (2008). Low-Carbon Economy and Environment of Financial Innovation. Shanghai Economic Research, (3), 38-42.

Yan, L. R., Lai, Y. W., Zhang, B., \& Li, Z. L. (2009). Boosting Low-Carbon Economic Development of the Green Financial Innovations. Fujian Finance, (12), 4-8. 